\title{
The Influence of Temporal Cake Moisture Content on a Discontinuous Washing Process in the Centrifugal Field
}

\author{
Franky Ruslim, Hermann Nirschl, and Werner Stahl \\ Institute of Mechanical Process Engineering and Mechanics, University of Karlsruhe (TH), Karlsruhe 76131, Germany \\ Philippe Carvin \\ RHODIA Research Center of Lyon, 85, rue des Frères Perret, BP 62, Saint-Fons Cedex 69192, France
}

DOI 10.1002/aic.11711

Published online February 5, 2009 in Wiley InterScience (www.interscience.wiley.com).

\begin{abstract}
In solidliquid separation processes, filter cake washing is an essential step in improving the quality of particulate products by elimination of impurities. During cake washing and dewatering, the cake saturation changes depending on the flow conditions and it cannot always be measured and controlled accurately. This article deals with investigations on the influence of the initial and temporal cake saturation on washing $P V C$ and silica sand particles in the centrifugal field. It was found, that high initial saturation levels and high maximum saturations during the washing process had a positive impact in inducing a high hydrostatic pressure for advective flow and enabling a homogeneous distribution of the wash water inside the cake. This was achieved by increasing the wash water flux andlor decreasing the g-factor. A good method to obtain low final impurity quantity is the combination of washing at a low g-factor and dewatering at a high one. (c) 2009 American Institute of Chemical Engineers AIChE J, 55: 650-662, 2009

Keywords: particle, filtration, centrifugation, solidlliquid separation, washing, purification
\end{abstract}

\section{Introduction}

Centrifugation is a widely used process in the chemical, pharmaceutical, food and biotechnical industries for purposes of mechanical dewatering and washing to obtain particulate products with low moisture content and impurity concentration. The possibility to apply high mass forces for liquid drainage, the relatively short process duration, high throughput and continuous as well as discontinuous operational modes are some of the advantageous which make centrifuges very attractive and applicable to many particulate products.

The dewatering process in the centrifugal field with the purpose of moisture content reduction has been subject of several

\footnotetext{
Correspondence concerning this article should be addressed to F. Ruslim at franky.ruslim@mvm.uni-karlsruhe.de.

(C) 2009 American Institute of Chemical Engineers
}

investigations. Some of the dewatering theories are based on empirical correlations such as in the work of Bender. ${ }^{1}$ Physical models of dewatering assuming a piston flow, ${ }^{2,3}$ a film flow ${ }^{4}$ and their superposition ${ }^{5,3}$ provide a good theoretical description of experimental data obtained from experiments. Hultsch ${ }^{6}$ and Stadager ${ }^{7}$ investigated the combination of differential pressure and centrifugal field for an enhanced dewatering process. The use of external forces was also subject of the investigations on steam centrifugation, performed by Peuker. ${ }^{8}$ Beiser $^{9}$ and $^{\text {Erk }}{ }^{10}$ dealt with sedimentation and rheological effects of fine particles in nonfiltering centrifuges.

The mechanical washing process in differential pressure field has been investigated by Bender, ${ }^{1}$ Nicolaou, ${ }^{11}$ Wakeman $^{12}$ and Heuser. ${ }^{13}$ Hoffner ${ }^{14}$ introduced a novel method of washing using a moving-bed apparatus, in which mechanisms of displacement and dilution wash were combined to achieve a high degree of product purity. 
Centrifugal washing has been investigated mostly for scale-up purposes, especially for products that are processed on multi-stage pusher centrifuges as discussed by Zürrer, ${ }^{15}$ Wakeman, ${ }^{16}$ Voitkovskii and Protsenko, ${ }^{17}$ Leung, ${ }^{18}$ and Stahl. ${ }^{19}$ In addition, theoretical models have been developed to enable a physical description of the washing process. Some of these models, e.g. side channel, film and dispersion model were presented in Kuo, ${ }^{20}$ Sherman, ${ }^{21}$ Wakeman, ${ }^{22-26}$ Rushton, ${ }^{27}$ Heuser $^{13}$ and Hoffner. ${ }^{14}$ Although the theoretical models are useful to indicate dominating mechanisms of washing by comparisons with experimental data, experiments are still required to determine material behavior under different process conditions.

A problem which may occur in washing processes performed in filtration apparatuses such as filters or centrifuges is the wash water maldistribution. This happens when washing thin and nonuniform cakes, ${ }^{12}$ cakes which are sensitive to cracks formation due to capillary or physico-chemical effects $^{11,13,28}$ or when the wash water application leads to a crater formation on the surface of cakes with instable solids structure. ${ }^{29}$ But even if the wash water distribution on the cake surface is very good, poor washing results can still be obtained, especially when the cakes have been pre-dewatered before wash water application. ${ }^{30,31}$ Inhomogeneous wash water distribution inside the cake during the multiphase flow due to embedded air was found to be responsible for this.

This work deals with an experimental approach in investigating the tempora! change of the moisture content of the filter cake during centrifugal washing. The correlation between the cake moisture content and the washing results provides important information in order to develop optimum process strategies in practical applications. The related industrial applications are solid/liquid separation processes on centrifuges, such as washing and dewatering of crystalline products on pusher centrifuges as well as in processing pharmaceutical products or fine chemicals in peeler centrifuges.

\section{Theoretical backgrounds}

A quantification of the void volume of a filter cake can be given by its porosity $\varepsilon$, which defines the portion of the pore volume $V_{\text {pores }}$ from the total cake volume $V_{\text {cake }}$

$$
\varepsilon=\frac{V_{\text {pores }}}{V_{\text {cake }}} \text {. }
$$

The saturation $S$ defines parts of the void volume which are filled by a volume of liquid $V_{\mathrm{L}}$,

$$
S=\frac{V_{\mathrm{L}}}{V_{\text {pores }}} .
$$

A possibility to quantify liquid accumulation on the cake surface is the volumetric liquid fraction $S^{*}$, defined as the multiple of sediment volume $V_{\text {cake }}$

$$
S^{*}=\frac{V_{\mathrm{L}}}{V_{\text {cake }}}=\frac{V_{\mathrm{L}} \cdot V_{\text {pores }}}{V_{\text {pores }} \cdot V_{\text {cake }}}=S \cdot \varepsilon,
$$

which can be calculated from the saturation and porosity, if the cake porosity remains constant during liquid accumulation.

The quantity of a solute in liquid can be given either as a concentration $c$, which is defined as the molar quantity $n$ divided by the liquid volume $V_{\mathrm{L}}$

$$
c=\frac{n}{V_{\mathrm{L}}},
$$

or as a loading $x$, which is defined as the mass of solute $m_{\text {solute }}$ divided by the solids mass $m_{\text {solids }}$

$$
x=\frac{m_{\text {solute }}}{m_{\text {solids }}} .
$$

The quality of the washing results is often given as concentration ratio $c^{*}$ which is the ratio between the final impurity concentration in the residual liquid inside the cake after washing $c$ and the initial impurity concentration in the mother liquor before washing $c^{*}$

$$
c^{*}=\frac{c}{c_{0}} \text {. }
$$

Although the impurity concentration ratio gives information on the quality of washing in terms of impurity concentration reduction, the loading ratio $x^{*}$ additionally takes into account the reduction of absolute impurity quantity because of dewatering of the pore liquid. It is defined as the ratio between the impurity loading in the residual liquid inside the cake after washing $x$ and the initial impurity loading in the mother liquor before washing $x_{0}$

$$
x^{*}=\frac{x}{x_{0}}=\frac{\frac{m_{\text {impurity }, \text { final }}}{m_{\mathrm{s}, \mathrm{final}}}}{\frac{m_{\text {impurity }, 0}}{m_{\mathrm{s}, 0}}} \stackrel{m_{\mathrm{s}}=\text { const. }}{\longrightarrow} \frac{m_{\text {impurity }, \mathrm{final}}}{m_{\text {impurity }, 0}} .
$$

According to Eq. 5, the impurity loading ratio is equal to the ratio between impurity mass after $\left(m_{\text {impurity,final }}\right)$ and before the washing process ( $m_{\text {impurity, } 0}$ ) if the final solids mass $\left(m_{\mathrm{S} \text {,final }}\right)$ is equal to the initial solids mass $\left(m_{\mathrm{S}, 0}\right)$.

In a wash diagram, the concentration or the loading ratio can be plotted against the wash ratio $W$ which results in a wash curve as shown in Figure 1.

The wash ratio is defined as the volume of applied wash water $V_{\mathrm{wl}}$ divided by the cake pore volume $V_{\text {pores }}$

$$
W=\frac{V_{\mathrm{wl}}}{V_{\text {pores }}}=\frac{Q_{\mathrm{wl}} \cdot t}{V_{\text {pores }}} .
$$

For a constant wash water flow rate $Q_{\mathrm{wl}}$, the wash ratio is proportional to the wash time $t$.

The ideal displacement curve is calculated under the assumption that during the washing process, a definite volume of wash water displaces the identical volume of mother liquor containing dissolved impurity as a piston flow. Considering the dewatering process as impurity removal, where the mother liquor along with the dissolved impurity is removed from the cake without adding any wash water, the concentration ratio of the ideal displacement can be calculated by

$$
\begin{aligned}
c_{\text {ideal displacement,deliquoring }}^{*} & \frac{c}{c_{0}}=\frac{\frac{c_{0} \cdot V_{\mathrm{ml}, \mathrm{eq}}-c_{0} \cdot V_{\mathrm{wl}}}{V_{\mathrm{ml}, \mathrm{eq}}}}{c_{0}} \\
= & \frac{\frac{V_{\mathrm{ml}, \mathrm{eq}}}{V_{\mathrm{pores}}}-\frac{V_{\mathrm{wl}}}{V_{\mathrm{pores}}}}{\frac{V_{\mathrm{ml}, \mathrm{eq}}}{V_{\mathrm{pores}}}}=\frac{S_{\mathrm{eq}}-W}{S_{\mathrm{eq}}},
\end{aligned}
$$

\section{AIChE Journal \\ March 2009 Vol. 55, No. 3 \\ Published on behalf of the AIChE \\ DOI 10.1002/aic}




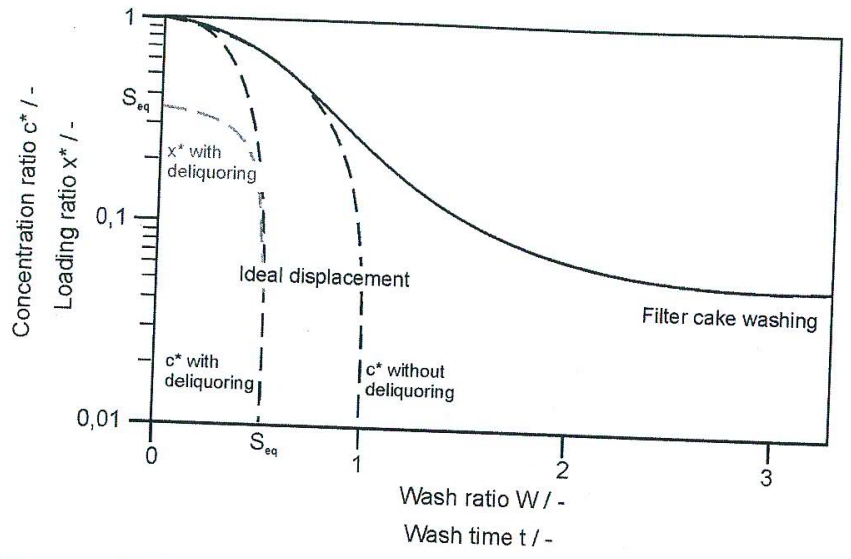

Figure 1. Schematic depiction of a wash curve for cake washing compared to the ideal displacement curve.

in which $S_{\text {eq }}$ is the cake equilibrium saturation, to which the cake is dewatered at a constant driving force. The loading ratio for ideal displacement can be calculated analogously by

$$
x_{\text {ideal displacement,deliquoring }}^{*}=\frac{x}{x_{0}}=S_{\text {eq }}-W .
$$

Experimental washing results follow normally the ideal displacement curve at low wash ratios. As the wash ratio increases, the wash curve deviates from the ideal displacement curve because of dispersion effects. Fried and Combarnous $^{32}$ mentioned three causes for mechanical dispersion which are a velocity profile in a capillary, differences in fluid velocity in capillaries of different sizes and a fluctuation of the flow path direction from the primary flow direction. The diffusion regime of the wash curve is characterized by a small decrease of the concentration or loading ratio with increasing wash ratio. The dominating mechanism in this regime is diffusion of the impurity from stagnant areas into the
primary flow.

\section{Experimental \\ Materials}

In this work, polyvinylchloride (PVC) particles and silica sand were used for the experiments. They exhibit a similar particle size distribution as depicted in Figure 2. The PVC particles were produced by radical suspension polymerization and the particles possessed a solids density of $1420 \mathrm{~kg} \mathrm{~m}^{-3}$ whereas the density of silica sand was measured to be 2650 $\mathrm{kg} \mathrm{m} \mathrm{m}^{-3}$. Filter cakes formed of PVC particles showed a porosity of 0.57 whereas silica sand cakes exhibited a lower porosity of 0.44 . The higher porosity of the PVC cakes was probably caused by the surface roughness in the form of crevices. The SEM images of the used materials are shown in Figure 3.

The impurity used in this study was pure sodium chloride $(\mathrm{NaCl})$ which was dissolved in deionized water. The deionization process was established by reverse osmosis and afterwards ion exchange process, so that a ground conductivity of $0-1 \mu \mathrm{S} \mathrm{cm}^{-1}$ was obtained. Deioinized water was also used

\section{Apparatus and experimental methodology}

All experiments in this work were done in a beaker centrifuge. It consisted of a rotor arm where two beakers of identical mass are placed inside. The rotational speed could be varied using a frequency converter. The rotational speed $n$ determined the so called "g-factor" $C$, which is the multiple of earth gravity, which was defined as

$$
C=\frac{\omega^{2} \cdot r}{g}=\frac{4 \cdot \pi^{2} \cdot n^{2} \cdot r}{g},
$$

in which $r$ is the centrifugation radius and $g$ the earth gravitational acceleration $\left(9.81 \mathrm{~m} \mathrm{~s}^{-2}\right)$.

The washing process was done in a cylindrical cake building area of $50 \mathrm{~mm}$ diameter and $60 \mathrm{~mm}$ height. The filtration area was calculated to be $1.96 \cdot 10^{-3} \mathrm{~m}^{2}$. The wash water was given by a full cone nozzle of type 556, manufactured by Schlick GmbH, Germany. The filtrate (also referred to as "wash effluent") flowed through a filter cloth (polyethylene, $41 \mu \mathrm{m}$, Sefar) and a filtrate outlet system into a reservoir (see Figure 4). The concentration of the impurity in the filtrate could be measured online by measuring the conductivity using a platinum electrode (Mostec $A G$ ). The temporal filtrate mass was determined indirectly by pressure measurements using a piezo resistive sensor with integrated Wheatstone bridge (Kistler Instrumente $A G$ ), which was placed inside the filtrate reservoir. A rubber diaphragm inside the outlet system prevented a reverse flow of drained filtrate into the cake after the experiment ended.

The initial impurity concentration was set to be $0.2 \mathrm{~mol}$ $1^{-1}$ for all experiments as a standard condition. The solid particles were introduced into the mother liquor and allowed to settle after stirring. The system reached an equilibrium state after 24 hours, where the measured conductivity did not significantly change upon time. No quantifiable sorption of the impurities on the solids surface was observed.

The cake was formed in earth gravity, where the suspension was given into the beaker at a high solids concentration. An initial cake thickness of $20 \mathrm{~mm}$ was set as a standard condition. After the cake is formed the saturation was set to one. Thus excess liquid on the cake surface was allowed to lary bre predominant pressure did not exceed the capillary pressure of the largest pore. The experiment started by centrifugation at a defined rotational speed. The wash water

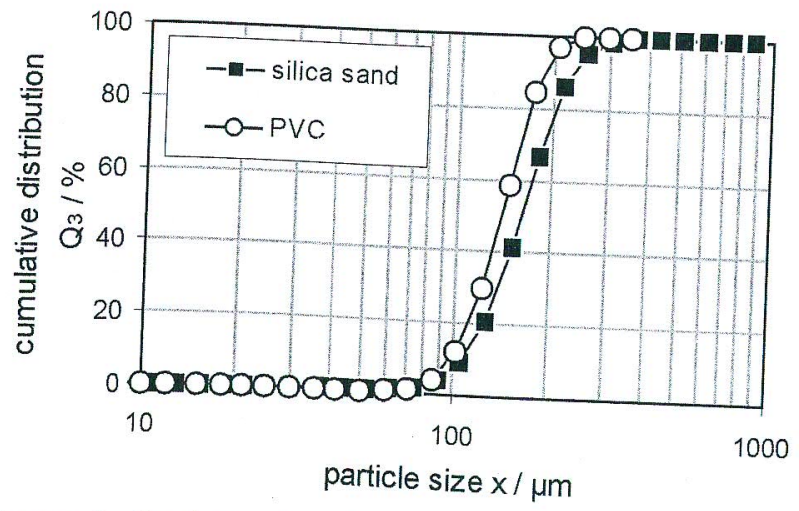
Figure 2. Particle size distributions of PVC and silica
sand.

March 2009 Vol. 55, No. 3 

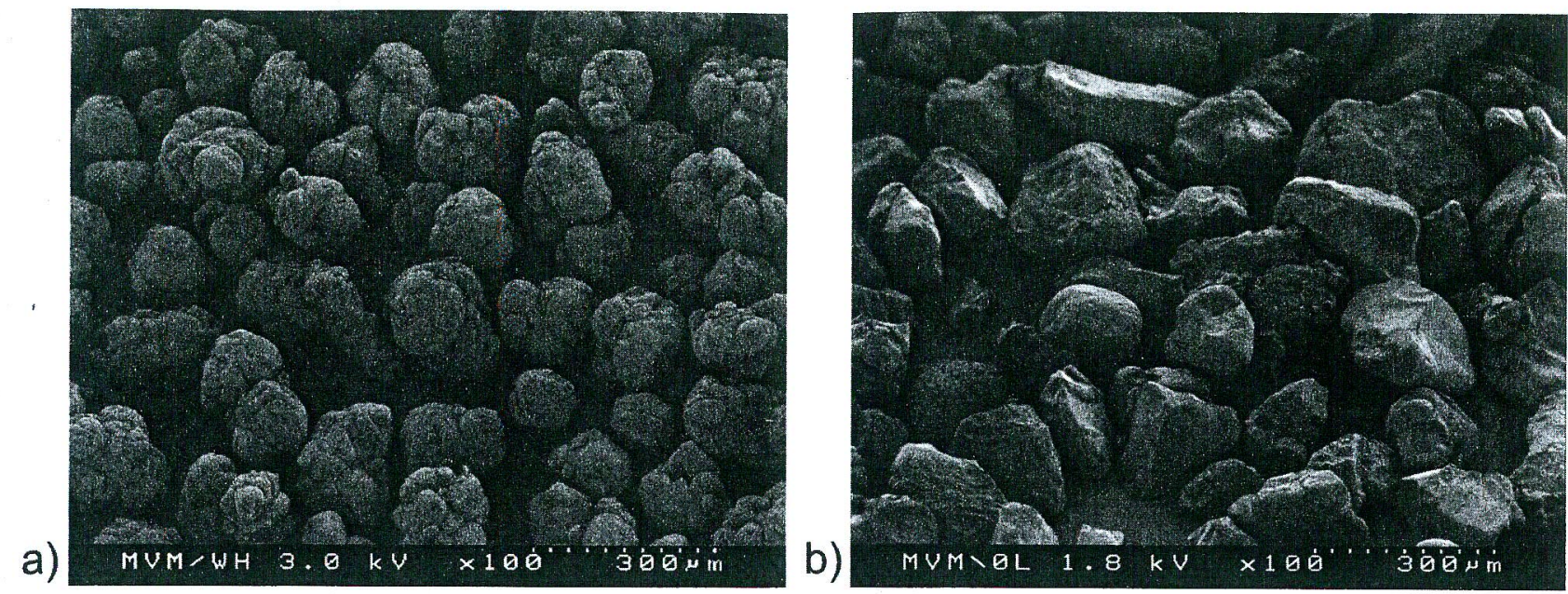

Figure 3. SEM images of PVC (a) and silica sand (b).

could be given either directly upon start or after a certain pre-dewatering time. The experiment ended when no liquid drained out of the cake, which could be monitored by the online mass signal.

Although an online measurement of the impurity concentration in the filtrate were viable, the determination of the impurity concentration was done offline by reslurrying the filter cake with a definite volume of deionized water
(100 $\mathrm{cm}^{3}$ water for $40 \mathrm{~cm}^{3}$ cake) and measuring the ionic conductivity in the liquid after intensive mixing of the solids and liquid. This was more relevant to the actual purpose of washing which was to obtain clean solid particles instead of clean filtrate. The online data was merely used to check the point of wash water breakthrough, the constancy of the conductivity after washing and conservation of mass within the system. To assure long-time stability of the measured values,

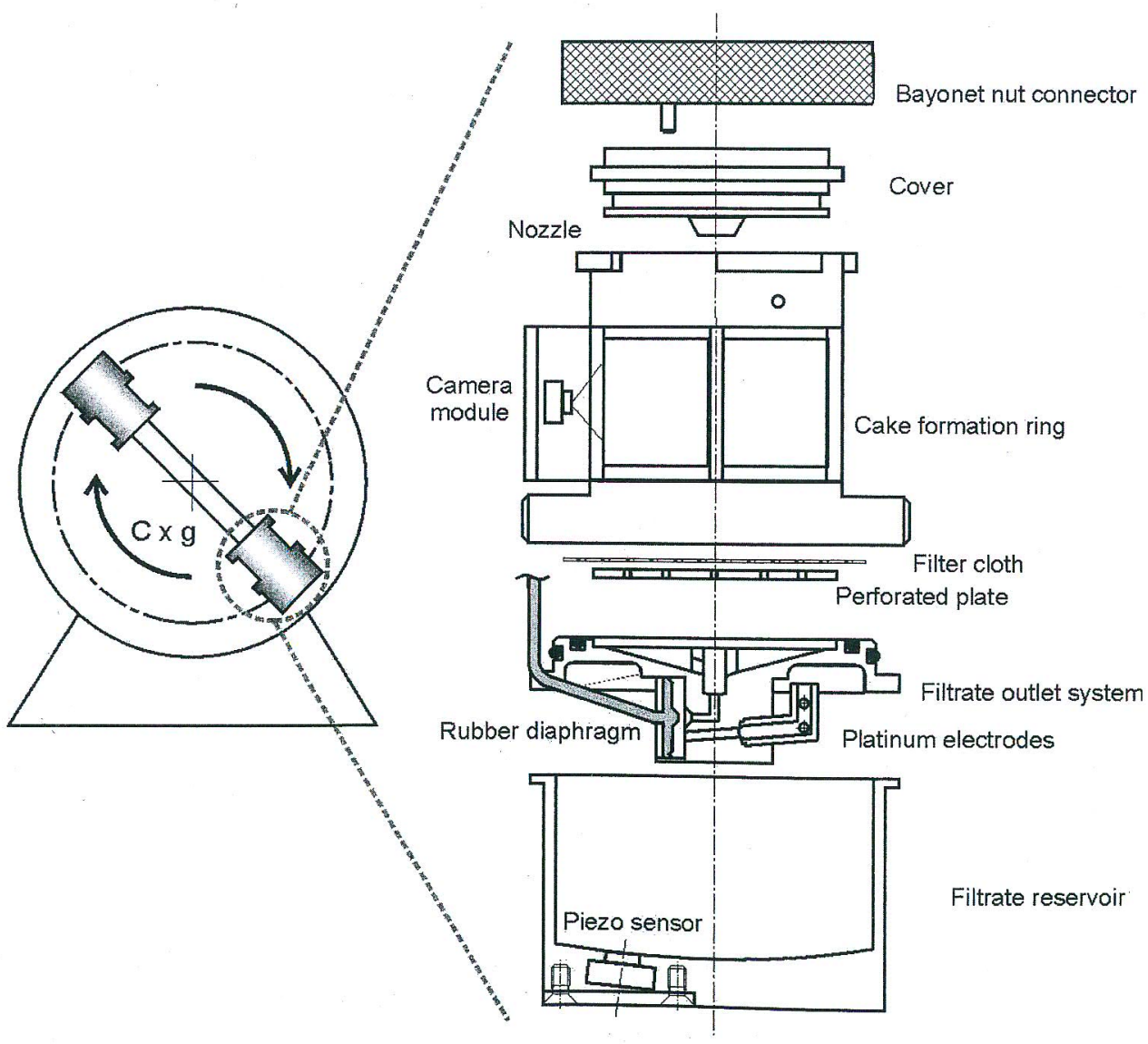

Figure 4. Setup of the beaker centrifuge. 


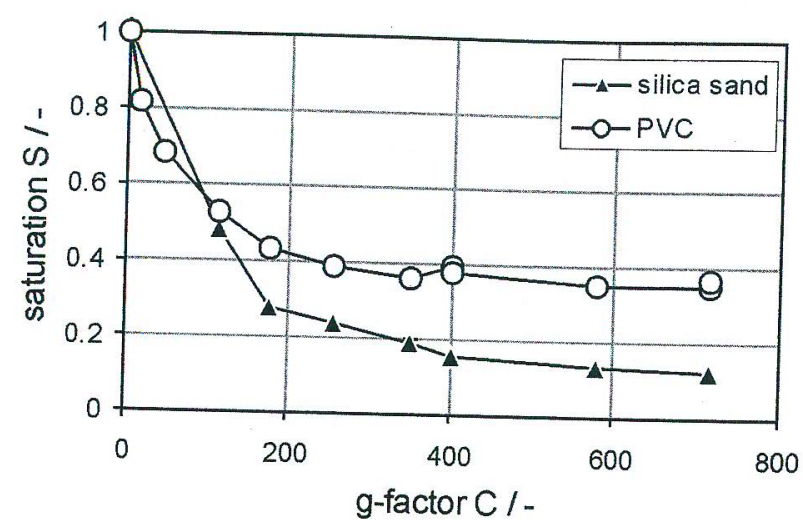

Figure 5. Equilibrium saturation as a function of the $\mathrm{g}$ factor measured for silica sand and PVC cakes of $20 \mathrm{~mm}$ thickness, variable g-factor.

multiple measurements were performed in definite intervals of time after reslurrying. The measured values were constant after $24 \mathrm{~h}$.

The possibility of performing several in situ measurements is one of the advantageous of the lab-scale beaker centrifuge. Moreover, the small size of the apparatus already allows data acquisition using a small amount of product sample. Indeed, not all of the real process parameters of continuous and discontinuous centrifuges can be simulated using the lab-scale beaker centrifuge. However, investigations on certain parameters by excluding the side-effects of other parameters are practicable. The transfer of some parameters to those of large-scale centrifuges (continuous and discontinuous) such as g-factor, filtration area, slurry concentration and flow rate, cycle time etc. is discussed in other papers ${ }^{19,18,33}$ in connection to several types of beaker centrifuge.

\section{Results and Discussion \\ Dewatering equilibrium and kinetics}

The dewatering behavior of cakes formed by both products is shown in Figure 5 as cake saturation against the g-factor C. The g-factor was varied by varying the rotational speed.

The equilibrium saturation decreased with increasing $g$ factor for both products. For g-factors higher than 400 , the decrease of the saturation became weaker with increasing gfactor. The saturation in this regime is also known as the "remanent saturation." The remanent saturation is the portion of liquid which is bonded stronger inside the cake than the capillary liquid and can not be removed significantly by means of mechanical forces. This was determined to be 0.1 for silica sand and 0.35 for PVC cakes. For silica sand cakes, the residual liquid was present mostly as liquid bridges and adsorbed liquid layer, whereas in PVC cakes, additional liquid was held by capillary forces in the deep surface rough-
ness. ${ }^{34}$

The dewatering kinetics of cake formed by both products is shown in Figure 6 as cake saturation against the dewatering time for a constant g-factor of 180 . The saturation decreased rapidly within the first seconds as the liquid drained out of the cake. After $5 \mathrm{~s}$, the decrease of the saturation with proceeding time became slower until the saturation reached its equilibrium state, corresponding to the equilibrium saturation in Figure 5 (0.44 for PVC and 0.27 for silica sand).

\section{Mechanical cake washing}

Influence of the Initial Cake Saturation. In a washing process, the wash water can be applied to the filter cake either when there is still a liquid accumulation on the cake surface or at different "initial" cake saturations $\left(1<\mathrm{S}_{0}<\right.$ $S_{\text {eq }}$ ) after the liquid has penetrated into the cake. A desaturation of the filter cake before washing is referred to as "predewatering." The later the wash water is applied, hence the longer the pre-dewatering time is, the lower is the initial cake saturation before washing $S_{0}$. Pre-dewatering was found to have a negative impact on the washing results, as reported by some authors as Wakeman, ${ }^{12}$ Fuchs et al. ${ }^{30}$ and Ruslim et al. ${ }^{35}$

The results depicted in Figure 7 showed the concentration ratio $c^{*}$ as a function of the wash ratio $W$ for silica sand cakes of $20 \mathrm{~mm}$ cake thickness at a constant g-factor of 180 and a wash water flux of $2.71 \mathrm{~m}^{-2} \mathrm{~s}^{-1}$. The wash water flux $J_{\mathrm{wl}}$ is the volumetric wash water flow rate $Q_{\mathrm{wl}}$ related to the filtration area $A_{\mathrm{f}}$ according to

$$
J_{\mathrm{wl}}=\frac{Q_{\mathrm{wl}}}{A_{\mathrm{f}}} .
$$

The silica sand cakes were washed instantly at a full cake saturation $\left(S_{0}=1\right)$ and after a pre-dewatering time of 15 seconds which corresponded to an initial cake saturation of $S_{0}=0.27$. For wash ratios below three, the concentration ratios of the pre-dewatered cakes were higher than those of the initially saturated cakes. This agreed to the findings of the authors mentioned above. The largest difference of the concentration ratios was observed in the dispersion regime and disappeared at wash ratios higher than three. Even slightly lower values of the concentration ratio were measured for pre-dewatered cakes.

The worsening of the washing results of the pre-dewatered cakes in the dispersion regime could have been caused by an inhomogeneous flow and distribution of the wash water inside the cake, as some areas were filled with air after predewatering. The presence of air made some capillaries inaccessible for the wash water, so that impurities in these capillaries could not be removed. Nevertheless, if a large amount

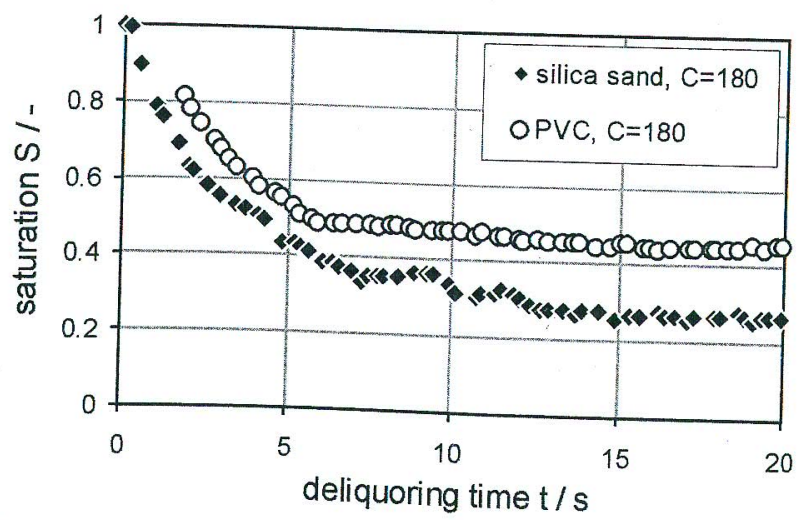

Figure 6. Temporary saturation as a function of the dewatering time measured for silica sand and PVC cakes of $20 \mathrm{~mm}$ thickness, $C=180$. 


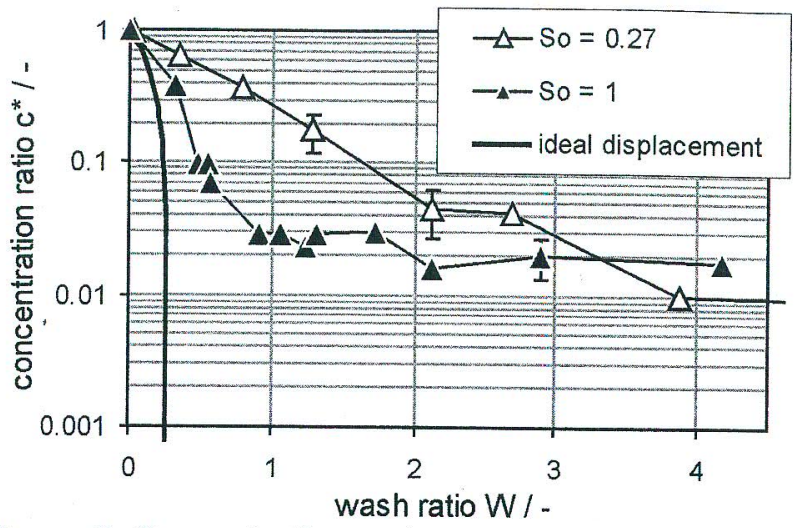

Figure 7. Concentration ratio $c^{*}$ as a function of the wash ratio $W$ measured for silica sand, $C=$ $180, \mathrm{~h}_{\mathrm{c}}=20 \mathrm{~mm}, \varepsilon=0.44, \mathrm{~J}_{\mathrm{wl}}=2.7 \mathrm{I} \mathrm{m}^{-2} \mathrm{~s}^{-1}$, $\mathrm{c}_{\mathrm{NaCl}, 0}=0.2 \mathrm{~mol} \mathrm{I}^{-1}$.

of wash water was given, low final impurity concentration ratios in the same order of magnitude as that of the initially saturated cakes could be achieved. The initially saturated cakes had the advantage that much lower wash water quantity was required to achieve low concentration ratios. For example, a concentration ratio of 0.029 was obtained for initially saturated cakes at a wash ratio of one compared to concentration ratios between 0.37 and 0.17 at a wash ratio around one for pre-dewatered cakes.

The results using PVC are depicted in Figure 8. In an experimental series, the wash water was given onto a saturated cake while in another; the cake was pre-dewatered $15 \mathrm{~s}$ before applying the wash water, so that an initial saturation of 0.44 was reached. Again, the negative impact of pre-dewatering on the washing results was observed. At the investigated wash ratios, the impurity concentration ratios of the pre-dewatered cakes were significantly higher than those of the initially saturated cakes. Even at a high wash ratio of 4.5 , the concentration ratio of the pre-dewatered cakes was at 0.15 , which was five times higher than that of the initially saturated cakes $\left[\mathrm{c}^{*}(\mathrm{~W}=4.2)=0.03\right]$. The severe worsening of the washing results of pre-dewatered PVC cakes, even at high wash ratios was probably caused by the poor wettability of the polymer particles and the distinct surface roughness as crevices. If the capillaries and crevices were empty at the time when the wash water was added, the wash water had to rewet the particle surface first, to be able to penetrate the capillaries. Air bubbles trapped inside the crevices might hinder a good distribution of the wash water. This resulted in an ineffective washing and an inefficient use of the wash water.

Influence of the Cake Saturation During Washing. During pre-dewatering, washing and postdewatering, the cake saturation changes dynamically. If a lab-scale centrifuge with online measurement technique is available, this temporal change of cake saturation can be observed during the process. However, online measurements and control of cake saturation are often not feasible in industrial processes. If material, machine and process parameters are known, the cake saturation progression can be approximated using a theoretical calculation. The calculation is based on determination of the temporal liquid volume inside the cake $V_{\mathrm{L} \text {,cake }}(t)$ using time discretization of a balance

$$
V_{\mathrm{L}, \mathrm{cake}}(t)=V_{\mathrm{L}, \mathrm{cake}}(t-\Delta t)+\left(Q_{\mathrm{wl}}-Q_{\mathrm{f}}(t-\Delta t)\right) \cdot \Delta t,
$$

in which $Q_{\mathrm{wl}}$ is the wash water mass flow rate, $Q_{f}(t-\Delta t)$ the temporal filtrate flow rate and $\Delta t$ the time interval for discretization.

For simplification of the calculation, the cake is considered to consist of two parts. The first part with a thickness of $h_{\mathrm{S} 1}$ exhibits a full saturation $S(\mathrm{t})=1$, whereas the other part with a thickness of $h_{\text {Seq }}$ possesses the equilibrium saturation $S(\mathrm{t})=$ $S_{\text {eq }}$ corresponding to the applied g-factor. The temporal filtrate flow rate $Q_{\mathrm{f}}(t)$ which is proportional to the temporal filtrate flux $J_{\mathrm{f}}(t)$ can be calculated based on the Darcy law

$$
\frac{Q_{\mathrm{f}}(t)}{A_{\mathrm{f}}}=J_{\mathrm{f}}(t)=\frac{\Delta p}{R \cdot \eta_{\mathrm{L}}}
$$

in which $\Delta p$ is the driving force for filtrate flow, $R$ the total flow resistance and $\eta_{\mathrm{L}}$ the dynamic viscosity of the liquid. Assuming a homogeneous, isotropic and incompressible filter cakes, equations developed from the Darcy law, which were presented by Peuker in Stahl ${ }^{19}$ could be used to calculate the filtrate flow rate or the filtrate flux

$$
\frac{Q_{\mathrm{f}}(t)}{A_{\mathrm{f}}}=J_{\mathrm{f}}(t)=\frac{2 \cdot \pi^{2} \cdot \rho_{\mathrm{L}} \cdot n^{2} \cdot\left(r_{\mathrm{cloth}}^{2}-r_{\mathrm{L}}^{2}(t)\right)}{\eta_{\mathrm{L}} \cdot\left[\left(r_{\mathrm{c}} \cdot h_{\mathrm{c}}\right)+R_{\mathrm{M}}\right]}
$$

in which $\rho_{\mathrm{L}}$ is the liquid density, $n$ the rotational speed, $r_{\text {cloth }}$ the centrifugation radius to the filter cloth, $r_{\mathrm{L}}(t)$ the temporal radius of the liquid surface, $A_{\mathrm{f}}$ the filtration area, $r_{\mathrm{c}}$ the specific cake resistance, $h_{\mathrm{c}}$ the cake thickness and $R_{\mathrm{M}}$ the filter cloth resistance.

The temporal centrifugation radius to the liquid level $r_{\mathrm{L}}(t)$ is calculated from the difference between the centrifugation radius to the filter cloth $r_{\text {cloth }}$ and the thickness of the saturated part of the cake $h_{\mathrm{S} 1}$

$$
r_{\mathrm{L}}(t)=r_{\text {cloth }}-h_{\mathrm{S} 1} \text {. }
$$

The thickness of the saturated part of the cake follows from a mass balance and becomes

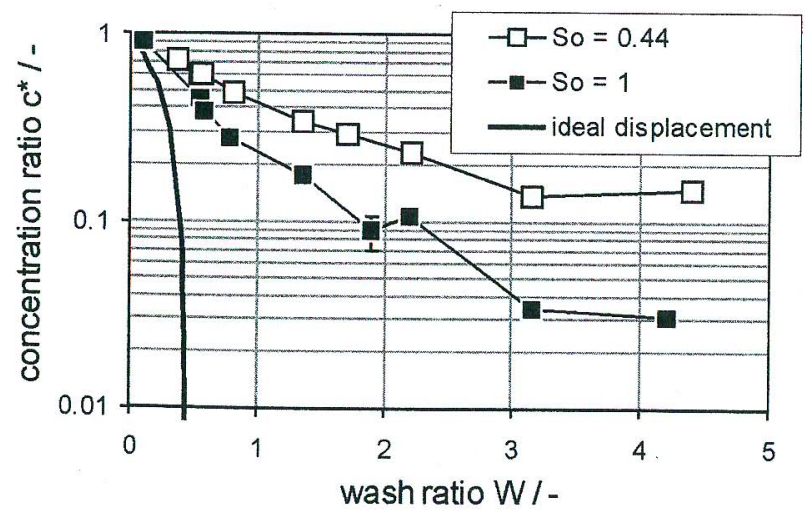

Figure 8. Concentration ratio $c^{*}$ as a function of the wash ratio $W$ measured for PVC, $C=180, h_{c}$ $=20 \mathrm{~mm}, \varepsilon=0.57, \mathrm{~J}_{\mathrm{wl}}=2.7 \mathrm{I} \mathrm{m}^{-2} \mathrm{~s}^{-1}, \mathrm{C}_{\mathrm{NaCl}, 0}$ $=0.2 \mathrm{~mol} \mathrm{I}^{-1}$. 
Table 1. Data for Calculation of the Temporal Saturation Progression of Silica Sand

\begin{tabular}{lcc}
\hline \multicolumn{1}{c}{ Parameter } & Value & Unit \\
\hline Filtration area & 0.0019635 & $\mathrm{~m}^{2}$ \\
Cake thickness & 0.02 & $\mathrm{~m}$ \\
Solids density & 2650 & $\mathrm{Kg} \mathrm{m}^{-3}$ \\
Cake porosity & 0.44 & - \\
Liquid dynamic viscosity & 0.001 & $\mathrm{~Pa} \mathrm{~s}^{-}$ \\
Specific cake resistance & $1.51 \times 10^{11}$ & $\mathrm{~m}^{-2}$ \\
Filter medium resistance & $1.0 \times 10^{10}$ & $\mathrm{~m}^{-1}$ \\
Equilibrium saturation & 0.27 & - \\
Rotational speed & 1000 & $\mathrm{~min}^{-1}$ \\
Radius to filter medium & 0.16 & $\mathrm{~m}$ \\
\hline
\end{tabular}

$$
h_{\mathrm{S} 1}(t)=\frac{\left(\frac{V_{\mathrm{L}, \mathrm{cake}}(t)}{A_{\mathrm{f}} \cdot \varepsilon}-S_{\mathrm{eq}} \cdot h_{\mathrm{c}}\right)}{1-S_{\mathrm{eq}}},
$$

in which $\varepsilon$ is the cake porosity, $S_{\text {eq }}$ the equilibrium saturation corresponding to the applied g-factor and $h_{\mathrm{c}}$ the total cake thickness.

A calculation was done for silica sand using the data listed in Table 1.

The parameters for the calculation were initialized using the material data according to Eqs. 18 to 24 .

$$
\begin{gathered}
S(t=0)=1, \\
h_{\mathrm{S} 1}(t=0)=h_{\mathrm{c}} \\
h_{\mathrm{S}_{\mathrm{eq}}}(t=0)=h_{\mathrm{c}}-h_{\mathrm{S} 1}(t=0), \\
V_{\mathrm{L}, \text { cake }}(t=0)=A_{f} \cdot \varepsilon \cdot\left(S_{\mathrm{eq}} \cdot h_{\mathrm{S}_{\mathrm{eq}}}(t=0)+h_{\mathrm{S} 1}(t=0)\right), \\
J_{\mathrm{f}}(t=0)=\frac{2 \cdot \pi^{2} \cdot \rho_{\mathrm{L}} \cdot n^{2} \cdot\left(r_{\mathrm{cloth}}^{2}-r_{\mathrm{L}}^{2}(t=0)\right)}{\eta_{\mathrm{L}}\left[\left(r_{\mathrm{c}} \cdot h_{\mathrm{c}}\right)+R_{\mathrm{M}}\right]} \\
r_{\mathrm{L}}(t=0)=r_{\mathrm{cloth}}-h_{\mathrm{S} 1}(t=0), \\
V_{\mathrm{f}}(t=0)=0 .
\end{gathered}
$$

The results of the calculation were compared to the experimental data from the online measurements as shown in Figure 9. Calculations were made for initially saturated cakes as well as for pre-dewatered cakes with a pre-dewatering time $t_{\mathrm{pd}}$ of $15 \mathrm{~s}$, with a time discretization interval $\Delta t$ of $0.1 \mathrm{~s}$.

Although significant differences were observed between the calculated saturations and the experimental data, a good approximation of the temporal saturation could be given. The largest deviations were seen mainly at the end of the predewatering phase and in the middle of washing, during liquid accumulation. The first was probably caused by inaccuracies of the online measurements because of dewatering of the filtrate outlet system and the later by fluctuations of the wash water flux due to nonideal behavior of the devices (pressure reducer, dead volume, nozzle, etc.). Nevertheless, the calculation provided a useful tool to aid determination of the saturation progression during the process sequences.

A further calculation of the saturation progression at different process conditions is depicted in Figure 10, in which some important notations of the cake saturation are presented.

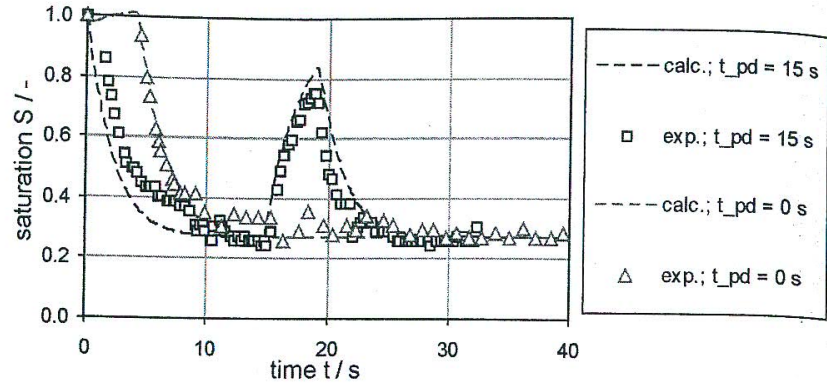

Figure 9. Temporal saturation as a function of time calculated and measured for silica sand, $\mathrm{C}=$ $180, h_{c}=20 \mathrm{~mm}, \varepsilon=0.44, J_{\mathrm{wl}}=2.7 \mathrm{I} \mathrm{m}^{-2} \mathrm{~s}^{-1}$, Os and $15 \mathrm{~s}$ pre-dewatering $\left(\mathrm{S}_{0}=1\right.$ and 0.27 respectively), $\mathrm{W}=1.2$.

After the cake has been pre-dewatered to a low saturation (referred to as "initial saturation" $\mathrm{S}_{0}$ ), a wash water addition can lead to an increase of the cake saturation. The highest saturation level during washing is referred to as the maximum wash saturation $S_{\max }$. Depending on the wash ratio, thus also the wash time, the saturation may reach a constant level at its steady state, where the wash water and filtrate fluxes are identical. The saturation progression during washing including the maximum saturation $S_{\max }$ is determined by the initial saturation $S_{0}$ as well as various material and process parameters.

In Figure 10, an increase of wash water flux leads to an increase of the maximum saturation at a constant wash ratio. The level of the steady state saturation is also elevated, provided that the wash water application is long enough to reach the steady state. A shorter wash water application or a lower wash ratio leads to a lower maximum saturation if the steady state has not been reached yet. If the steady state has been reached, the maximum saturation equals the steady state saturation. The final cake saturation after postdewatering is referred to as "equilibrium saturation" $S_{\text {eq }}$ corresponding to the applied driving force.

To account for the various material and process parameters, which influence the saturation progression, a flow ratio $F R$ was defined similar as in the paper of Ruslim et al. ${ }^{31}$ as

$$
\mathrm{FR}=\frac{J_{\mathrm{wl}}}{J_{\text {filtrate,Darcy }}},
$$

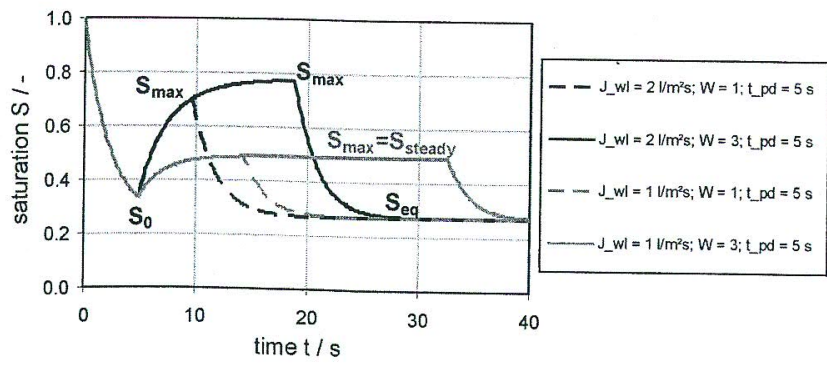

Figure 10. Temporal saturation as a function of time calculated for silica sand, $C=180, h_{c}=20$ $\mathrm{mm}, \varepsilon=0.44, \mathrm{~J}_{\mathrm{wl}}=1$ and $21 \mathrm{~m}^{-2} \mathrm{~s}^{-1}, 5 \mathrm{~s}$ pre-dewatering, $W=1$ and 3 . 


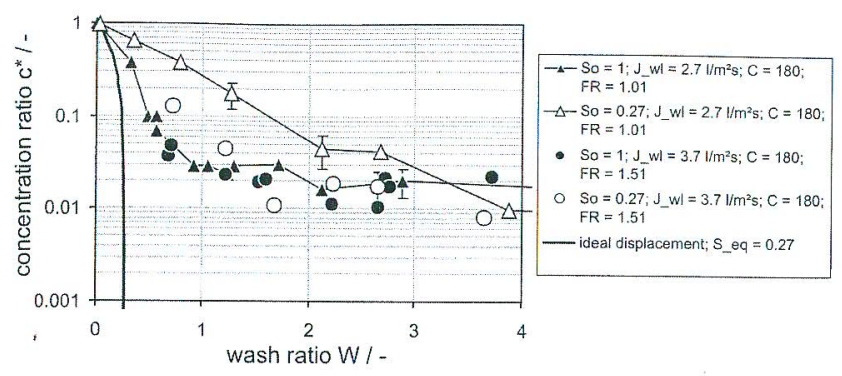

Figure 11. Impurity concentration ratio as a function of flow ratio measured for silica sand, $h_{c}=20$ $\mathrm{mm}, \varepsilon=0.44$, various flow ratios.

in which $J_{\text {filtrate,Darcy }}$ is the maximum filtrate flux in a singlephase flow calculated by the law of Darcy. The flow ratio $F R$ could be varied either by changing the wash water flux $J_{\mathrm{wl}}$ or by changing the Darcy filtrate flux, for example through variation of the g-factor, which is proportional to the driving force $\Delta p$ in Eq. 14 of the Darcy's law.

For identical wash ratios $W$ and initial saturation $S_{0}$, a higher maximum saturation $S_{\max }$ can be achieved by using a higher flow ratio $F R$. If the high flow ratio results from an increase of the wash water flux, then the high maximum saturation can be reached faster or within a shorter wash time than at lower wash water fluxes.

The washing results of silica sand at different wash and flow ratios are shown in Figure 11. The washing results at a wash water flux $J_{\mathrm{wl}}$ of $2.71 \mathrm{~m}^{-2} \mathrm{~s}^{-1}$ and a g-factor $C$ of 180 should be regarded as a reference in comparison to the other results obtained by variation of the initial saturation, wash water flux and g-factor. An increase of the flow ratio $F R$ from 1.01 to 1.51 by increasing the wash water flux $J_{\mathrm{wl}}$ to $3.71 \mathrm{~m}^{-2} \mathrm{~s}^{-1}$ led to an improvement of the washing results of pre-dewatered cakes $\left(S_{0}=0.27\right)$, in terms of lower impurity concentration ratios, whereas the results of not pre-dewatered cakes $\left(S_{0}=1\right)$ remained unaffected.

The washing results of PVC at different wash and flow ratios are shown in Figure 12. Analogue to Figure 11, the washing results at a wash water flux $J_{\mathrm{wl}}$ of $2.71 \mathrm{~m}^{-2} \mathrm{~s}^{-1}$ and a g-factor $C$ of 180 should be regarded as a reference in comparison to the other results obtained by variation of the initial saturation, wash water flux and g-factor. An increase of the flow ratio $F R$ from 0.91 to 1.36 by increasing the wash water flux $J_{\mathrm{wl}}$ to $3.71 \mathrm{~m}^{-2} \mathrm{~s}^{-1}$ led to an improvement of the washing results of pre-dewatered cakes $\left(S_{0}=0.44\right)$, in terms of lower impurity concentration ratios, whereas the results of not pre-dewatered cakes $\left(S_{0}=1\right)$ remained unaffected.

As many factors influence the washing process, the explanation for the different behaviors at various parameter combinations is rather complex. An approach will be given using the concept of "dynamic cake saturation." Here, the dynamic change of the saturation during washing is considered to have a very strong impact on the results.

The flow ratio and the initial saturation determine decisively the progression of the temporal saturation $S_{\text {wash }}(t)$. In Table 2, a case distinction is made regarding the flow ratio and the initial saturation.
For a flow ratio of one, meaning that the wash water flux is equal to the maximum filtrate flux, the cake will remain saturated if the cake has not been pre-dewatered at the time of wash water application, hence the initial saturation is one $\left(S_{0}=1\right)$. If the initial saturation is lower than one after predewatering, the saturation $S_{\text {wash }}(t)$ will increase during washing.

For high flow ratios FR $>1$, the cake can be flooded as the wash water accumulates on the cake surface, when the initial saturation equals to one $\left(S_{0}=1\right)$. Otherwise, if the cake has been pre-dewatered to an initial saturation below one $\left(S_{0}<1\right)$, the liquid level will rise and the pores will be refilled.

For low flow ratios FR $<1$ and if the cake is fully saturated at the beginning $\left(S_{0}=1\right)$, the saturation decreases during washing. On the other hand, if the cake has already been pre-dewatered $\left(S_{0}<1\right)$, it is not obvious whether the saturation then increases or decreases. If the initial saturation $S_{0}$ is lower than the steady state saturation $S_{\text {steady }}$ then the temporal saturation will increase. This is the case when the wash water flux $J_{\mathrm{wl}}$ is higher than the filtrate flux corresponding to the initial saturation $J_{\text {filtrate }}\left(S_{0}\right)$. Otherwise the cake will continue to desaturate toward the steady state saturation level.

The wash ratio, which is proportional to the wash time, also determines the maximum reachable saturation during the washing process. After the steady state has been reached, the maximum wash saturation becomes constant. An increase of the wash ratio at this point merely leads to a longer duration of washing without a further increase of the maximum washing saturation.

Based on the considerations regarding the parameters mentioned above, several mechanisms which may happen during washing are proposed as depicted in Figure 13.

If a pre-dewatered cake still possesses a significantly higher saturation than the remanent cake saturation, the residual mother liquor is present not only as liquid bridges and adsorbed liquid layer but also inside cake capillaries in void volumes of the cake. This can exert direct influence on the flow mechanism during wash water application. As soon as the wash water penetrates into the cake, it meets the surface of the mother liquor inside the capillaries. The flow ratio determines the displacement mechanism. At a high flow ratio, a piston displacement (A2) is more likely to happen than at a lower flow ratio. If the mother liquor flows faster than the incoming wash water, it leaves empty capillaries which

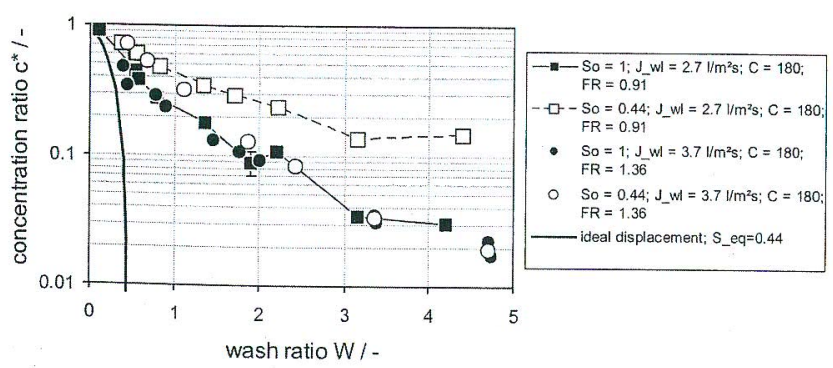

Figure 12. Impurity concentration ratio as a function of flow ratio measured for $\mathrm{PVC}, \mathrm{h}_{\mathrm{c}}=20 \mathrm{~mm}, \varepsilon$ $=0.57$, various flow ratios. 
Table 2. Regimes of the Flow Ratio FR

\begin{tabular}{cccc}
\hline FR & Comparison & $S_{0}=1$ & $S_{0}<1$ \\
\hline 1 & $J_{\text {w1 }}=J_{\text {filtrate,Darcy }}$ & $S_{\text {wash }}(t)=$ constant $=1$ & $S_{\text {wash }}(t)$ increases \\
$>1$ & $J_{\text {w1 }}>J_{\text {filtrate,Darcy }}$ & $S_{\text {wash }}(t)$ increases $>1$ & $S_{\text {wash }}(t)$ increases \\
& $J_{\text {w1 }}<J_{\text {filtrate,Darcy }}$ & $S_{\text {wash }}(t)$ decreases $<1$ & $S_{\text {wash }}(t)$ increases if $J_{\text {wl }}>J_{\text {filtrate }}\left(S_{0}\right)$ \\
& & $S_{\text {wash }}(t)$ decreases if $J_{\text {wl }}<J_{\text {filtrate }}\left(S_{0}\right)$ \\
\hline
\end{tabular}

are to be filled by the wash water. Here, the wash water must first wet the particle surface and does not contribute directly to a piston displacement of the mother liquor (A1).

If a pre-dewatered cake possesses an initial saturation similar to the remanent cake saturation, the residual mother liquor remains as stagnant liquids such as liquid bridges, adsorbed liquid layer and liquids retained inside deep surface roughness. These liquids can not be removed easily by means of mechanical forces. As soon as the wash water is applied onto the cake, it rewets the particle surface to penetrate into the empty cake capillaries. The wetting process depends on the interaction energy between solid and liquid. ${ }^{36}$ If this is lower than in between the liquid, poor wetting may occur, for example between polymer particles and water. The presence of air can also hinder the rewetting process and may also block several capillaries so that the wash water has no access into them. This is more likely to happen when washing at a low flow ratio (B1). The dominant mechanism of washing is dilution of liquid bridges, provided that the wash water can access these areas. A piston displacement of the mother liquor by the wash water can only be achieved if working at a high flow ratio (B2). Here, a large quantity of wash water can rapidly come into contact with the residual mother liquor and contribute to impurity removal by piston displacement. The high advective force is also advantageous for a homogeneous flow and distribution of the wash water in the capillaries.

If the cake is fully saturated at the time of wash water application, mechanisms of displacement, dispersion and diffusion can happen simultaneously and contribute to impurity removal. However, if the flow ratio is very low, mechanisms described as A1 or A2 for pre-dewatered cakes can begin to take effect.

The washing results of pre-dewatered silica sand cakes at a flow ratio of 1.01 could be improved by increasing the flow ratio to 1.51 . This indicated that the impurity removal during washing the pre-dewatered cakes was limited by the poor contact between the mother and wash water as depicted in mechanism B1. An increase of the flow ratio led to a significant improvement of the results. The fact that the variation of flow ratio, either by increasing the wash water flux or by increasing the g-factor, did not affect the washing results of initially saturated cakes, suggested a sufficient contact between the wash and mother liquor at the investigated parameters.

The flow ratios determined for the washing results of silica sand were generally higher than those of PVC. This was mainly due to the higher specific cake resistance of the silica sand cakes $\left(15 \times 10^{10} \mathrm{~m}^{-2}\right)$ compared to that of the PVC cakes $\left(2.2 \times 10^{10} \mathrm{~m}^{-2}\right)$. The washing results of pre-dewatered PVC cakes at a flow ratio of 0.91 could be improved by an increase of the flow ratio to 1.36 . Analogue to the results of silica sand, the limitation, and problem of washing pre-dewatered cakes was often the insufficient contact between the mother and wash water due to inhomogeneous flow and distribution, so that mass transfer mechanisms for impurity removal can not take place properly. Because of poor water-wettability of polymeric materials, the rewetting process of the surface of the PVC particles was more difficult than for hydrophilic materials such as silica. In addition, the rough surface structure with deep crevices which still contained residual mother liquor with dissolved impurity was difficult to be accessed by the wash water if it was blocked by air. Thus high impurity concentration ratios were obtained.

The correlation of the results and the maximum liquid saturation which ensued during the washing process at the investigated parameters is shown in Figure 14 for silica sand. As the saturation exceeds one at some conditions, the saturation looses its physical meaning because of its definition. Thus the volumetric liquid fraction $S^{*}$ should be used to

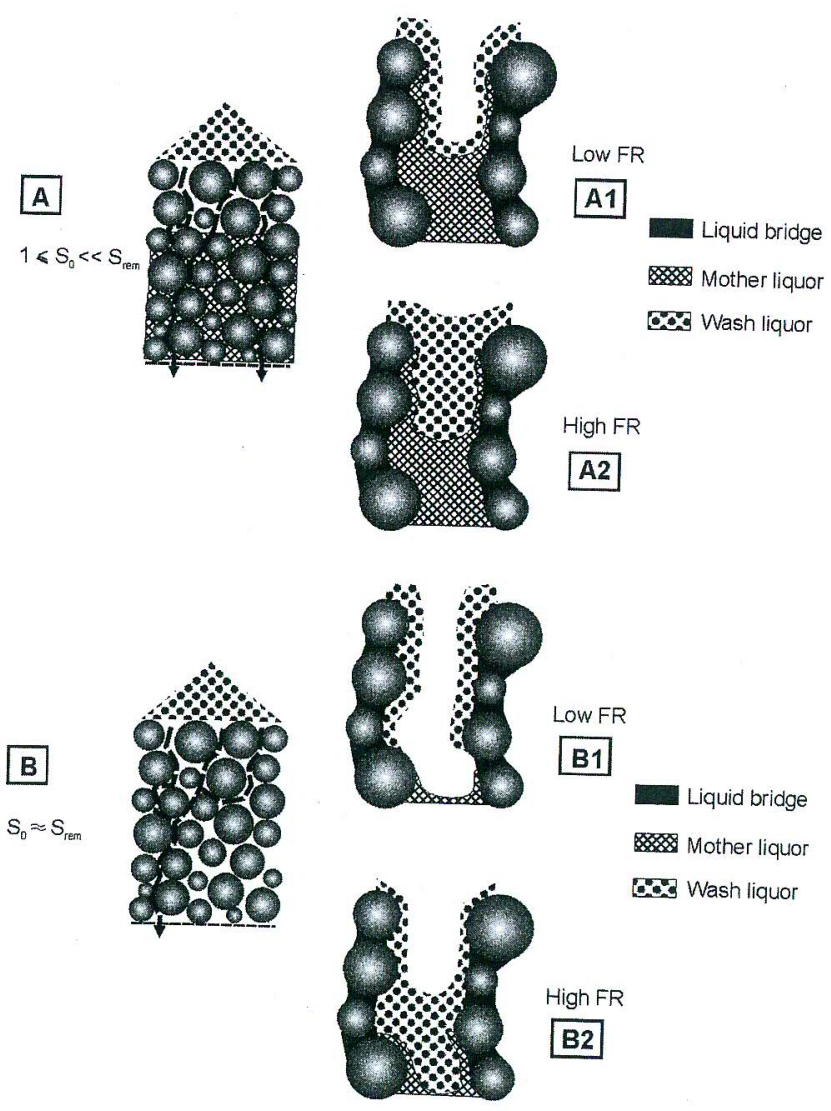

Figure 13. Proposed mechanisms during washing at various parameter combinations. 


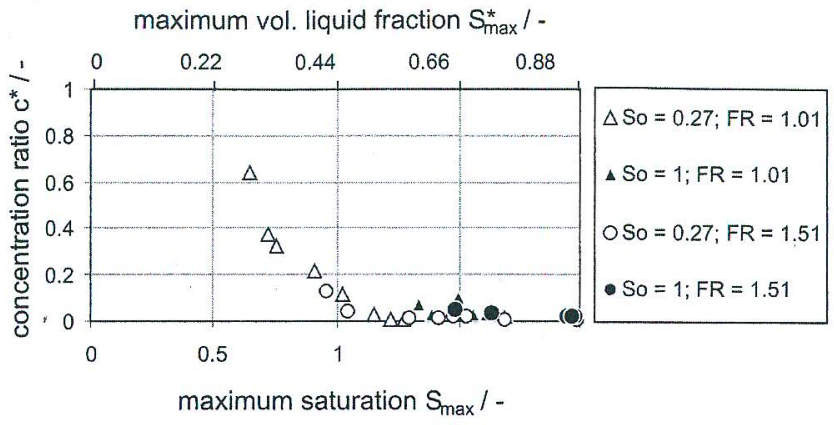

Figure 14. Impurity concentration ratio as a function of the maximum wash saturation measured for silica sand, $h_{c}=20 \mathrm{~mm}, \varepsilon=0.44$, various wash ratios and flow ratios.

quantify liquid accumulation on the cake surface instead of the saturation.

The maximum saturation seemed to have a strong impact on the impurity concentration ratios, especially for saturation values below one. This was the case when the cakes had been pre-dewatered before washing $\left(S_{0}=0.27\right)$. The lower the achievable maximum saturation was, the higher was the impurity concentration ratios. For maximum liquid fractions higher than 0.44 , no significant impact of the liquid fraction on the concentration ratio could be observed.

Low maximum saturations were measured for pre-dewatered cakes with low initial saturations, low flow ratios and low wash ratios. Whenever these conditions prevailed, inhomogeneous liquid flow and distribution led to formation of areas which were not directly accessible for the wash water. In contrary, a high maximum saturation could be achieved at a high flow ratio, initial saturation and wash ratio. These process conditions enforced a refill of the cake capillaries by the accumulating liquid, making the stagnant areas accessible for the wash water and enabling mass transfer mechanisms for impurity removal.

The dependency of the washing results for PVC on the maximum saturation $S_{\max }$ or the maximum volumetric liquid fraction $S_{\max }^{*}$ is presented in Figure 15. Similar to silica sand, a significant influence of the maximum saturation on the im-

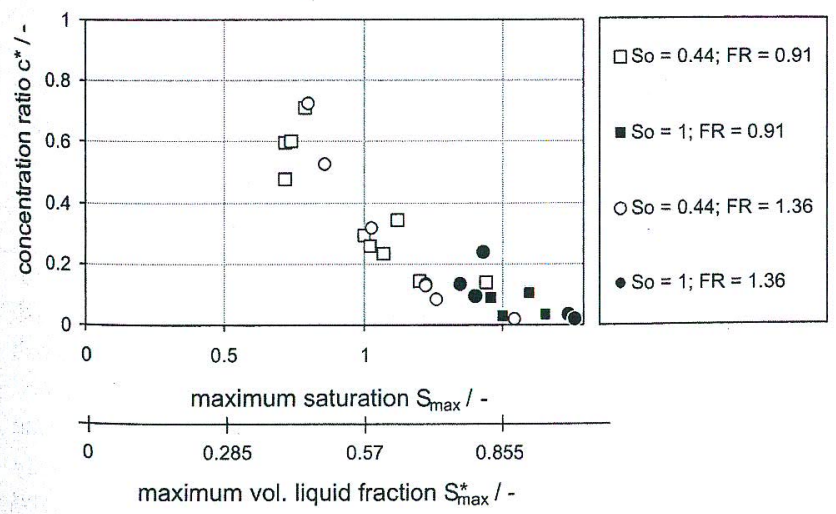

Figure 15. Impurity concentration ratio as a function of the maximum wash saturation measured for PVC, $\mathrm{h}_{\mathrm{c}}=20 \mathrm{~mm}, \varepsilon=0.57$, various wash ratios and flow ratios. purity concentration ratio was observed. The lower the maximum saturation was the higher was the measured concentration ratio.

An interesting result was found by analyzing the impurity concentration ratios of cakes with similar maximum saturations or liquid fractions but different flow ratios and wash ratios. These are presented exemplarily for PVC in Table 3 for two cake thicknesses. Cakes of $20 \mathrm{~mm}$ thickness washed at a maximum liquid fraction of 0.69 , a flow ratio of 1.36 and a wash ratio of 1.87 possessed an impurity concentration ratio which was $11 \%$ lower than that of cakes washed at a lower flow ratio of 0.91 and a higher wash ratio of 4.39 . This suggested that the influence of flow ratio on the washing results was stronger than that of the wash ratio at identical conditions. Therefore it was more advantageous to reach a high maximum saturation by setting a high wash water flux rather than by setting a high wash ratio, hence a longer wash time, at a lower wash water flux during washing. The same results were observed for silica sand.

At a maximum liquid fraction of 0.58 , an opposite impact of the high flow ratio was observed. The impurity concentration ratio of the cakes washed at a flow ratio of 0.91 and a wash ratio of 2.34 was $18 \%$ lower than that of the cakes washed at a higher flow ratio of 1.36 and a lower wash ratio of 1.11. The fact that the wash ratio, hence the wash time, also had a dominant influence on the results in addition to the maximum saturation indicated that diffusion mechanism played an important role during washing of PVC cakes. This could be explained by the complex surface roughness structure of PVC with deep crevices, which allowed retention of mother liquor with dissolved impurities. As these areas were probably not directly accessible for the main flow of the wash water, the impurity had to diffuse out of the crevices into the open areas to be washed out by the wash water (see Figure 16).

Influence of the Final Cake Saturation After Washing and Dewatering. An increase of g-factor, for example by increasing the rotational speed, leads to a higher acceleration of the liquids. An increase of the filtrate flux will lead to a decrease of the flow ratio $F R$ and can cause a poor contact between the wash and mother liquor. On the other hand, increasing the g-factor can accelerate and enhance the dewatering process if the remanent saturation has not been reached yet. The influence of different g-factors and the final equilibrium saturation on the washing results in terms of concentration and loading ratio is presented representatively using the results of PVC in Figure 17.

The concentration ratio increased with increasing g-factor and thus decreasing flow ratio, for the reasons explained in the previous chapter. However, the loading ratio first decreased with increasing g-factor until $\mathrm{C}=200$ at low

Table 3. Comparison of the Influence of Flow Ratio and Wash Ratio on the Washing Results of PVC

\begin{tabular}{ccccc}
\hline$h_{\mathrm{c}} / \mathrm{mm}$ & $S_{\max }^{*}$ & FR & $W$ & $c^{*} /-$ \\
\hline 20 & 0.68 & 0.91 & 4.39 & 0.146 \\
20 & 0.69 & 1.36 & 1.87 & 0.130 \\
20 & 0.58 & 0.91 & 2.34 & 0.259 \\
20 & 0.58 & 1.36 & 1.11 & 0.317 \\
30 & 0.53 & 0.89 & 1.26 & 0.323 \\
30 & 0.53 & 1.34 & 1.17 & 0.274 \\
\hline
\end{tabular}




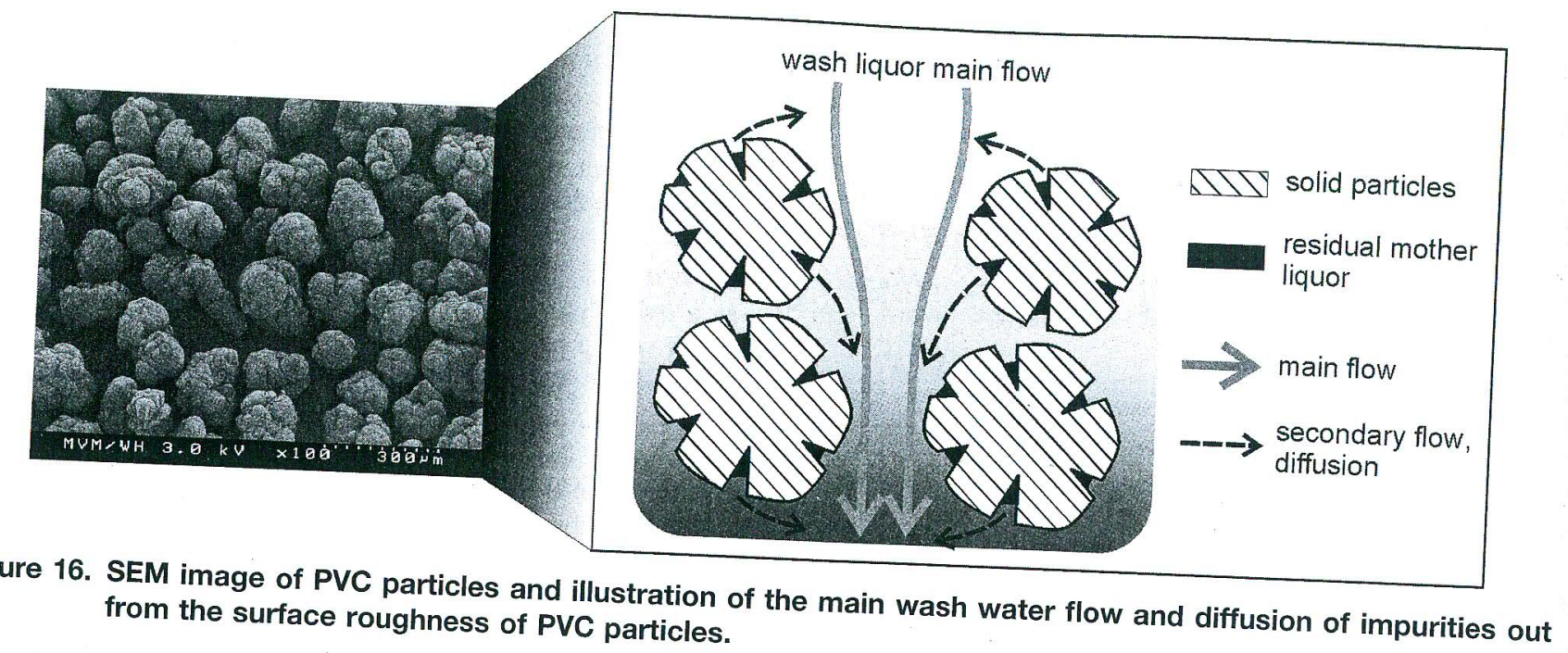

The applie therefi Lowes and $\mathrm{r}$ enhan to bet tion $d$ If this factor well, to obl at a li

AckI

The DIA $\mathrm{R}$

wash ratios of 0.7 and 1.1. A further increase of the g-factor led to an increase of the loading ratio.

While the impurity concentration ratio quantifies the quality of washing in terms of impurity concentration reduction the loading ratio additionally takes into account the reduction liquid. Thus although quantity due to dewatering of the pore reached after the low impurity concentrations were liquid inside the cake process, a large volume of residual impurity. An optimum could still contain a large quantity of there was a sufficient condition could be achieved when mass transfer contact between the liquids so that at the same time take place (at relative low g-factors) and cake by sufficient enough liquid could be removed out of the

Unfortunately, working at the optimum g-factor is not always advantageous because of low throughput. In this case, a possible solution to obtain low impurity quantities is to

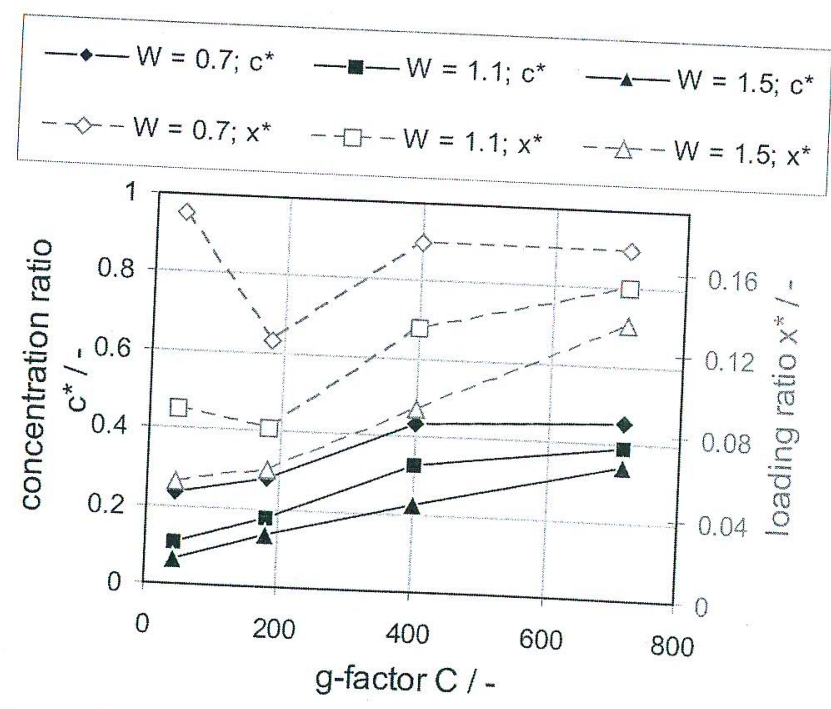

Figure 17. Impurity concentration and loading ratio as a function of the $\mathrm{g}$-factor measured fo PVC, $h_{c}=20 \mathrm{~mm}, J_{w l}=2.71 \mathrm{~m}^{-2} \mathrm{~s}^{-1}, \mathrm{C}_{\mathrm{NaCl}}$ $=0.2 \mathrm{~mol} \mathrm{l}^{-1}$, no pre-dewatering $\left(S_{0}=1\right)$.

separate the tasks of washing and dewatering, for example by washing at a low g-factor and afterwards increasing the g-factor for postdewatering until the cake reaches a low equi-
librium saturation.

Note

\section{Conclusions}

Dewatering filter cakes before wash water application was found to have a negative impact on the washing results, in terms of the remaining impurity concentration ratio. Besides the initial saturation, the temporal saturation level of the cake during the washing process also seemed to strongly influence the washing results.

If the initial saturation was low, washing at low flow ratios was found to be disadvantageous because of inhomogeneous inside cake distribution of the wash water inside the cake. Air lead to a capillaries might block the wash water flow and lead to a formation of stagnant areas. Residual mother liquor by the wash remaining in these areas could not be removed impurity ros transfer mechanism for the wash and moth limited by the poor contact between

A possible solution to this

for example solution to this was to increase the flow ratio, for example by increasing the wash water flux. This way, the uor and conthe a better contact with the mothhigh flow ratio led to displacement washing. Moreover, a and a high maximum a liquid accumulation inside the cake ily. In contrary, poor aration could be achieved temporarmaximum saturion washing results were obtained at low maximum saturations, which was the case when washing at The better and/or low initial saturations.

tion was to wash to achieve a definite high maximum saturaratio instead of a high wash water flux and a low wash water flux. This way, at high wash ratio and a low wash rapidly. The advantages maximum saturation was reached reduction of wash water were the shorter wash time, the concentration rion lower impurity impurity out of surfacerer, if diffusion of the dissolved wash times and/or hige roughness limited the process, longer influence on the washing wash ratios also had a positive saturation. 
The equilibrium cake saturation was determined by the applied g-factor. The g-factor influenced the flow ratio and therefore had a significant impact on the washing results. Lower g-factors were advantageous because high flow ratios and high maximum saturations could be achieved. These enhanced the flow and distribution of the wash water and led to better washing results. Moreover, the equilibrium saturation determined the residual liquid quantity inside the cake. If this was large, for example when dewatering at a low gfactor, the measured absolute impurity quantity was large as well, despite the low impurity concentration. A good method to obtain a low final impurity quantity was to wash the cake at a low g-factor and to dewater it at a higher g-factor.

\section{Acknowledgments}

The authors gratefully acknowledge the financial support from RHODIA Research Centre of Lyon which made this project possible.

\section{Notation}

$A_{\mathrm{f}}=$ filtration area $\left(\mathrm{m}^{2}\right.$

$C=$ g-factor

$c=$ concentration $\left(\mathrm{mol} \mathrm{l}^{-1}\right)$

$c^{*}=$ concentration ratio

$c_{0}=$ initial concentration $\left(\mathrm{mol} \cdot \mathrm{l}^{-1}\right.$ )

$\mathrm{FR}=$ flow ratio

$h_{\mathrm{c}}=$ cake thickness $(\mathrm{mm})$

$h_{\mathrm{S} 1}=$ cake thickness of full saturation $(\mathrm{mm})$

$h_{\text {Seq }}=$ cake thickness of equilibrium saturation (mm)

$J_{\text {filtrate,Darcy }}=$ maximum filtrate flux according to Darcy $\left(1 \mathrm{~m}^{-2} \mathrm{~s}^{-1}\right)$

$J_{\mathrm{wl}}=$ wash water flux $\left(1 \mathrm{~m}^{-2} \mathrm{~s}^{-1}\right)$

$m_{\text {impurity,final }}=$ final impurity mass inside the cake $(\mathrm{g})$

$m_{\text {impurity }, 0}=$ initial impurity mass inside the cake $(\mathrm{g})$

$m_{\mathrm{L}}=$ liquid mass $(\mathrm{g})$

$m_{\text {solids }}=$ solids mass $(\mathrm{g})$

$m_{\text {solute }}=$ solute mass $(\mathrm{g})$

$n=$ rotational speed $\left(\mathrm{min}^{-1}\right)$

$Q_{\mathrm{wl}}=$ wash water flow rate $\left(\mathrm{ml} \mathrm{s}^{-1}\right)$

$Q_{\mathrm{f}}=$ filtrate flow rate $\left(\mathrm{ml} \mathrm{s}^{-1}\right)$

$r_{\mathrm{c}}=$ specific cake resistance $\left(\mathrm{m}^{-2}\right)$

$r_{\text {cloth }}=$ centrifugation radius to the filter cloth (m)

$r_{\mathrm{L}}=$ centrifugation radius to the liquid level $(\mathrm{m})$

$R_{\mathrm{M}}=$ filter medium resistance $\left(\mathrm{m}^{-1}\right)$

$S=$ saturation

$S_{\text {steady }}=$ saturation at steady state (stationary level)

$S^{*}=$ volumetric liquid fraction

$S_{0}=$ initial cake saturation before washing

$S_{\text {eq }}=$ equilibrium saturation corresponding to the applied g-factor

$S_{\max }=$ maximum saturation during washing

$S_{\text {rem }}=$ remanent saturation

$V_{\text {cake }}=$ cake volume $\left(\mathrm{cm}^{3}\right)$

$V_{\mathrm{L}}=$ liquid volume $(\mathrm{ml})$

$V_{\text {pores }}=$ pore volume $\left(\mathrm{cm}^{3}\right)$

$W=$ wash ratio

$x=$ particle size $(\mu \mathrm{m})$

$x=$ loading

$x^{*}=$ loading ratio

$\Delta p=$ difference pressure $(\mathrm{Pa})$

$\Delta \eta=$ dynamic viscosity $(\mathrm{Pa} \mathrm{s})$

$\varepsilon=$ porosity

$\rho=$ density $\left(\mathrm{kg} \mathrm{m}^{-3}\right)$

\section{Literature Cited}

1. Bender W. Das Auswaschen von Filterkuchen. Chem-Ing-Tech 1983;55:823-829.
2. Zeitsch K. Eine neue Theorie der Zentrifugalentfeuchtung. Chemische Technik. 1981;33:456-461.

3. Reif F, König H, Wünsch M, Stahl W. Entfeuchtungskinetik von feinkörnigen Produkten im Zentrifugalfeld. Aufbereitungs-Technik. 1990;31:117-125.

4. Mayer G. Die Beschreibung des Entfeuchtungsverhaltens von körnigen Haufwerken im Fliehkraftfeld. PhD Thesis, University of Karlsruhe (TH), 1986.

5. Batel W. Vorgänge bei der mechanischen Entwässerung. Chem Ing Tech. 1954;26:497-502.

6. Hultsch G. Feststoffentfeuchtung durch simultane Druck- und Zentrifugalfiltration. Chem Ing Tech. 1988;60:76.

7. Stadager C. Die Entfeuchtung von Filterkuchen durch die Kombination von Zentrifugal- und Gasdruckkraft. $\mathrm{PhD}$ Thesis, University of Karlsruhe (TH), 1995.

8. Peuker U. Über die kombinierte Dampfdruck- und Zentrifugalentfeuchtung von Filterkuchen. $\mathrm{PhD}$ Thesis, University of Karlsruhe (TH), 2002.

9. Beiser M. Sedimentationsverhalten submikroner Partikeln in Abhängigkeit physikalisch-chemischer Einflüsse und ihr Separationsverhalten in Dekantierzentrifugen. $\mathrm{PhD}$ Thesis, University of Karlsruhe (TH), 2005.

10. Erk A. Rheologische Eigenschaften feindisperser Suspensionen während ihrer Fest-Flüssig-Trennung in Filtern und Zentrifugen. PhD Thesis, University of Karlsruhe (TH), 2006;11.

11. Nicolaou I. Fortschritte in Theorie und Praxis der Filterkuchenbildung und -entfeuchtung durch Gasdruckdifferenz. PhD Dissertation, University of Karlsruhe (TH), 1996.

12. Wakeman RJ. Washing thin and nonuniform filter cakes: effects of wash liquor maldistribution. Filtr Sep.1998:185-190.

13. Heuser J. Filterkuchenwaschprozesse unter besonderer Berücksichtigung physikalisch-chemischer Einflüsse. $\mathrm{PhD}$ Thesis, Universität Karlsruhe (TH), 2003.

14. Hoffner B. Ein neuartiges Verfahren zur Feststoffwaschung die Anwendung des Wanderbetts zur hochgradigen Aufreinigung partikulaer-disperser Systeme. PhD Thesis, University of Karlsruhe (TH), 2006.

15. Zürrer H. Waschprozesse in mehrstufigen Schubzentrifugen. Chemische Rundschau. 1973;28:16-21.

16. Wakeman RJ. Process design and scale-up of multi-stage washing pusher centrifuges. Filtr Sep. 1985:231-234.

17. Voitkovskii BF, Protsenko AV. Effect of washing on quality of a crystalline product. Koks I Khimiya. 1988;2:49-51.

18. Leung WW-F. Industrial Centrifugation Technology. New York: McGraw-Hill, 1998.

19. Stahl W. Fest-Fluessig-Trennung, Band II: industriezentrifugenmaschinen und Verfahrenstechnik. Männedorf: DrM Press, 2004.

20. Kuo M. Filter cake washing performance. AIChE J. 1960;6:566-568.

21. Sherman WR. The movement of a soluble material during the washing of a bed of packed solids. AIChE J. 1964;10:855-860.

22. Wakeman RJ. Prediction of the washing performance of drained filter cakes. Filtr Sep. July/August 1972:409-415.

23. Wakeman RJ, Rushton A. A structural model for filter cake washing. Chem Eng Sci. 1974;29:1857-1865.

24. Wakeman RJ. Diffusional extraction from hydrodynamically stagnant regions in porous media. Chem Eng J.1976:39-56.

25. Wakeman RJ. The estimation of cake washing characteristics. Filtr Sep. January/February 1980:67-73.

26. Wakeman RJ, Attwood GJ. Simulations of dispersion phenomena in filter cake washing. Trans IChemE.1990:161-171.

27. Rushton A. Centrifugal filtration, dewatering and washing. Filtr Sep. September/October 1981:410-415.

28. Wiedemann T. Das Schrumpfungs- und Rissbildungsverhalten. $\mathrm{PhD}$ Thesis, University of Karlsruhe (TH), 1996.

29. Berger W, Ernst H, Khai VQ. Abtragung von Filterkuchen durch strömende Flüssigkeit. Chem Techn. 1990;42:123-125.

30. Fuchs B, Peuker U, Stahl W. The influence of the pre-dewatering time and the feed-rate of the wash liquid on the filter-cake washing in the centrifugal field.AFS Congress, Reno, Nevada, 2003.

31. Ruslim F, Nirschl H, Stahl W, Carvin P. Optimization of the wash liquor flow rate to improve washing of pre-deliquored filter cakes. Chem Eng Sci. 2007;62:3951-3961.

32. Fried J, Combarnous M. Dispersion in porous media. Adv Hydrosci. 1971;7:169-282. 
33. Ruslim F, Fleischer J, Nirschl H, Peuker U. Filterkuchenwäsche zur Aufreinigung loeslicher, kristalliner Feststoffpartikel. Chem Ing Tech. 2006;78:715-719.

34. Wünsch M. Decanter, Worm Screen or Pusher Centrifuge, Science Makes the Decision Easy. American Filtration Society (AFS) Annual Meeting, Chicago, 1992.

35. Ruslim F, Nirschl H, Stahl W, Carvin P. The Impact of Pre-Dewatering on Washing Filter Cakes by Mass Forces. FIL TECH, Wiesbaden, Germany, 2005.

36. de Gennes PG. Wetting: statics and dynamics. Rev Mod Phys. 1985;57:827-863.

37. Hoffner B, Fuchs B, Heuser J. Washing processes for disperse particulate systems-Process spectrum and aspects for the process choice. Chem Eng Technol. 2004;27:1065-1071.
38. Ruslim F, Linkenheil N, Nirschl H, Stahl W, Carvin P. Modified lab-scale beaker centrifuge as a tool for investigations of filter cake washing processes. Aufbereitungs- Technik. 2006;11:20-31.

39. Ruslim F, Nirschl H, Stahl W, Carvin P. Optimization strategies in purifying dispersed particulate solids. World Congress on Particle Technology, Orlando, 2006.

40. van Swaaij WPM. Residence time distribution in the liquid phase of trickle flow in packed columns. Chem Eng Sci. 1969;24:1083-1095.

41. Veksler GB. Hydrodynamics of the cake washing process in filtering centrifuges. New Mach Equip. 1987;3:85-89.

42. Zhukov VG. Centrifugal washing of residue collected from a filter bed. Teor Osn Khim Tekhnol. 1984;18:142-147.

Manuscript received Apr. 29, 2008, and revision received Aug. 16, 2008. 